\title{
Layanan penerbitan ilmiah LIPI Press di masa pandemi Covid-19
}

\author{
Dhevi Enlivena Irene Restia Mahelingga \\ dhevlingga@gmail.com \\ Balai Media dan Reproduksi LIPI
}

\begin{abstract}
ABSTRAK: Wabah corona atau pandemi Covid-19 membuka peluang untuk integrasi dan interaksi digital dalam penyelenggaraan layanan publik, tidak terkecuali layanan penerbitan ilmiah. LIPI Press selama pandemi Covid19 telah beradaptasi dengan integrasi dan interaksi digital melalui kebijakan layanan publik yang berbasis teknologi informasi. Beberapa layanannya, antara lain optimalisasi website dan media sosial; internalisasi sistem penerbitan ilmiah melalui Open Monograph Press; penyelenggaraan webinar; pemanfaatan e-office; dan knowledge sharing secara daring.
\end{abstract}

Kata Kunci Layanan; Penerbitan Ilmiah; LIPI Press; Covid-19.

\section{PENDAHULUAN}

Sejalan dengan otoritas ilmiah LIPI Press dan sesuai dengan amanah ketetapan Peraturan Kepala LIPI No.6 tahun 2020 tentang Organisasi dan Tata Kerja Balai Media dan Reproduksi. (Perka LIPI No. 6 Tahun 2020 Tentang Organisasi Dan Tata Kerja Balai Media Dan Reproduksi, 2020) LIPI Press mempunyai tugas melakukan perencanaan, pengakuisisian, pengemasan, dan penyebarluasan informasi ilmu pengetahuan kepada masyarakat. Dalam pelaksanaannya, LIPI Press memiliki fungsi pemberian layanan pemerolehan (akuisisi) informasi ilmu pengetahuan. Fungsi tersebut menjadikan kontribusi LIPI Press semakin signifikan, karena tidak hanya mengemban sebuah program berskala nasional melainkan juga sebagai ikon LIPI di hadapan publik.

Layanan penerbitan ilmiah LIPI Press berkembang tidak hanya menjadi sebuah total solusi penerbitan, melainkan juga dalam aspek akuisisi pengetahuan lokal untuk dikemas dan didiseminasikan kepada masyarakat. Peningkatan kapasitas tersebut memacu LIPI Press untuk meningkatkan kinerjanya secara efektif dan efisien. Terlebih dengan adanya wabah Corona atau pandemi Covid-19 pada awal 2020 membuat LIPI Press berinovasi dalam layanannya dengan membuka peluang untuk integrasi dan interaksi digital. (Mahelingga, 2020d)

Penggunaan alat digital oleh para akademisi untuk konferensi, kuliah, dan rapat selama karantina wilayah membuktikan bahwa teknologi informasi yang tersedia saat ini dapat menggantikan banyak interaksi kerja fisik secara memadai. Format interaksi digital memungkinkan pertukaran dan kolaborasi antara individu dan kelompok kerja yang berjarak satu sama lain secara spasial. (Schwarz et al., 2020)

Berdasarkan pertimbangan tersebut, beberapa kegiatan perbaikan dan inovasi yang telah dilaksanakan LIPI Press dalam peningkatan kualitas layanan publik berbasis interaksi digital adalah sebagai berikut.

\section{PEMBAHASAN}

\section{Integrasi Layanan Berbasis Teknologi Informasi}

Layanan LIPI Press telah menggunakan teknologi informasi yang terintegrasi dalam website lipipress.lipi.go.id, baik akses seputar informasi terbitan, layanan sistem penerbitan ilmiah (e-service), layanan digital library, layanan e-learning, maupun dokumen internal sistem manajemen mutu. Dengan

\footnotetext{
${ }^{1}$ Dipublikasikan dalam Laporan Pelaksanaan Reformasi Birokrasi Balai Media dan Reproduksi LIPI Press 2020.
} 
demikian, semua layanan telah terintegrasi dan dapat diakses melalui satu pintu lipipress.lipi.go.id. Seiring dengan meluasnya ruang lingkup LIPI Press dalam layanan multimedia, konten multimedia (dokumenter dan animasi) juga telah terintegrasi ke dalam website. seperti:

Melalui website lipipress.lipi.go.id ini juga ditampilkan berbagai macam informasi layanan

1) Standar Pelayanan LIPI Press sesuai SK-039a/JI.7/KP/IV/2017 Penetapan Standar Pelayanan Penerbitan Ilmiah UPT Balai Media dan Reproduksi (LIPI Press)

2) Maklumat Pelayanan LIPI Press sesuai SK-039/JI.7/I-KP/IV/2017 tentang Penetapan Maklumat Pelayanan, Sanksi, dan Kompensasi Ketidaksesuaian Standar Pelayanan Penerbitan UPT Balai Media dan Reproduksi (LIPI Press).

3) SOP bagi pelaksanaan standar pelayanan berupa SMM Bidang Layanan Penerbitan Ilmiah beserta Prosedur Layanan Penerbitan Ilmiah

4) Website juga menampilkan feeds dari berbagai media sosial LIPI Press (Facebook, Instagram, dan Twitter) dan informasi terkait Whatsapp PPID untuk mempercepat tindak lanjut keluhan pelanggan.

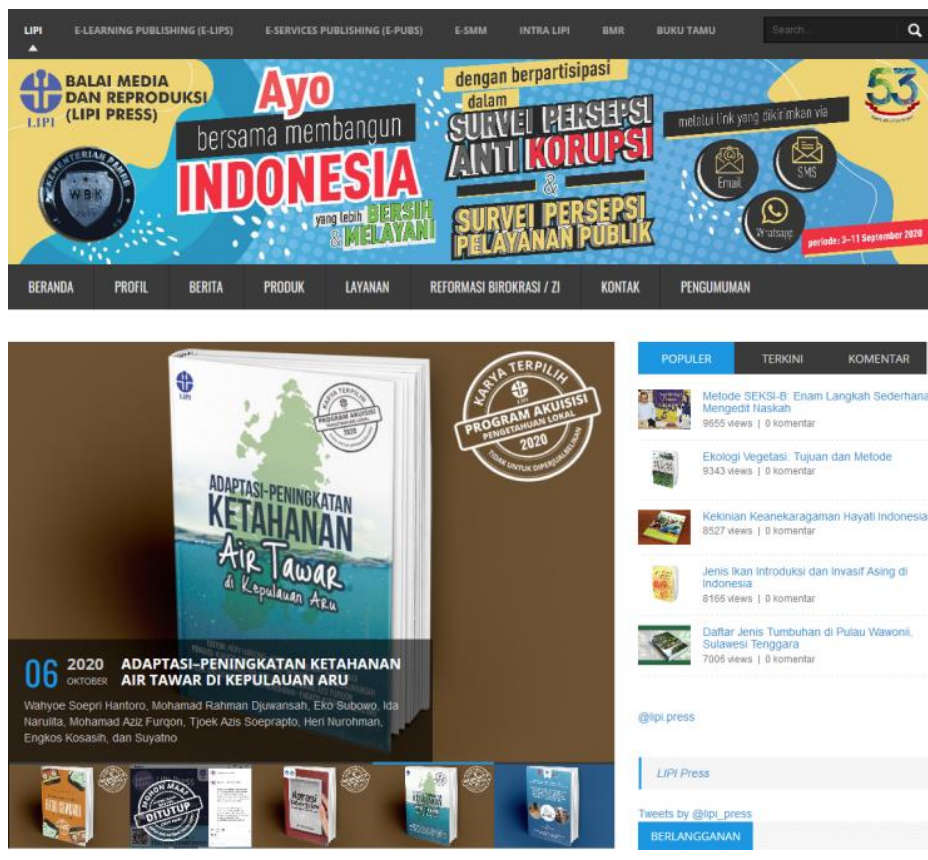

Gambar 1 Layanan Terintegrasi melalui Website lipipress.lipi.go.id

\section{Inovasi Layanan Sistem Penerbitan Ilmiah Daring (e-service)}

LIPI Press berinovasi dalam mengembangkan layanan penerbitan ilmiah daring (online) melalui e-service.lipipress.lipi.go.id. Pada 2019 LIPI Press mengembangkan inovasi tersebut dengan mengaplikasikan sistem sumber terbuka berbasis Open Monograph Press (OMP). Sistem OMP mampu mengakomodasi secara daring kebutuhan alur kerja penerbitan buku, dari naskah masuk, verifikasi, penelaahan (review), penyuntingan (copyediting), tata letak, desain sampul, proofreading (production), hingga terbit dalam katalog yang dapat diakses publik. (Mahelingga, 2020b)

OMP sendiri dirancang secara efisien untuk mengurangi waktu dan tenaga yang dibutuhkan untuk tugas-tugas substansial dan manajerial yang terkait dengan penerbitan buku sekaligus meningkatkan proses pencatatan dan efisiensi proses editorial. (Mahelingga, 2020a) Selain kebutuhan internal penerbit, sistem OMP juga mengakomodasi kebutuhan akademisi (dosen, peneliti, mahasiswa) dalam indeksasi dan sitasi. Melalui OMP, naskah yang terbit dapat terindeks oleh Google Scholar dan memungkinkan tersitasi secara lebih luas. Kemampuannya untuk dapat diindeks oleh situs-situs pengindeks memudahkan masyarakat luas khususnya akademisi global dalam mencari terbitan LIPI Press melalui berbagai platform. 
antara lain:

Secara umum, sistem e-service.lipipress.lipi.go.id berbasis OMP ini memiliki berbagai fitur,

1) menunjang kebutuhan akademisi (peneliti/dosen) untuk mendapatkan indeks/sitasi;

2) mendukung kanal publik LIPI Press berbentuk digital library yang memudahkan masyarakat luas dalam mengakses ilmu pengetahuan; dan

3) mengakomodasi kegiatan penerbitan LIPI Press secara daring dan full e-book tahun 2020.

Hasil dari inovasi ini adalah pada tahun 2020, sebanyak 244 terbitan LIPI Press telah diunggah di sistem OMP dan dapat dinikmati oleh masyarakat secara bebas, akses penuh, dan dapat diunduh gratis.

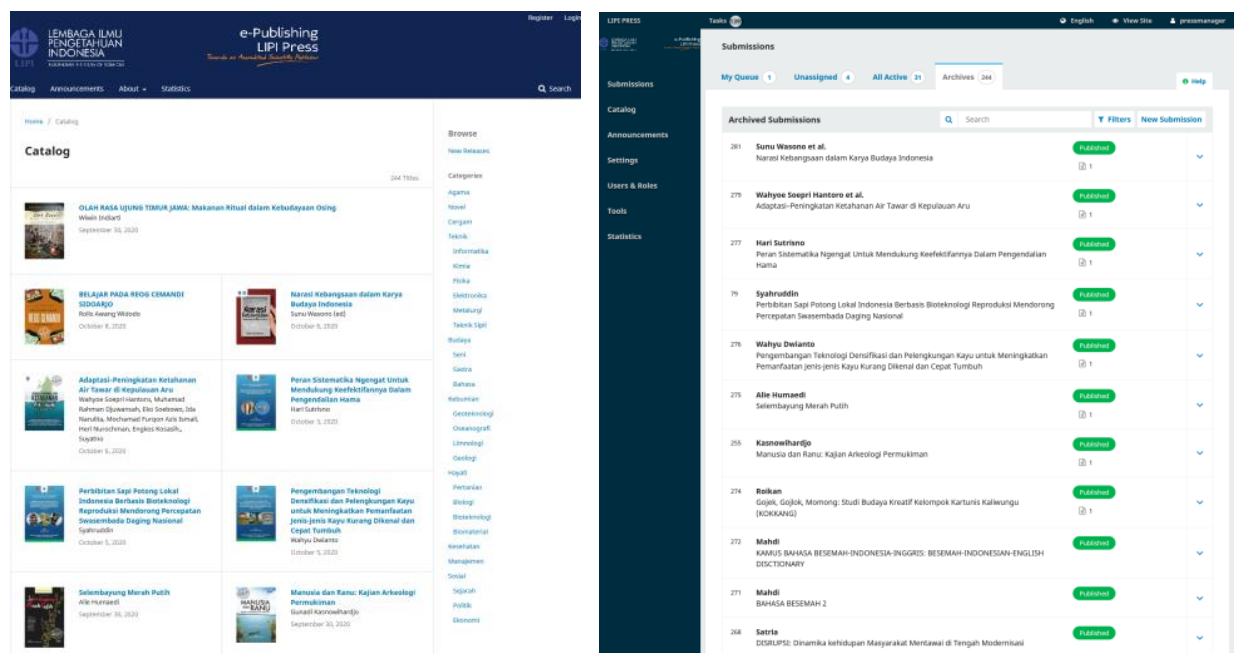

Gambar 2. Sistem OMP LIPI Press Mengakomodasi Penerbitan Ilmiah Daring dan Digital Library

\section{Capaian Layanan Sistem Penerbitan Ilmiah Daring (e-service)}

Pada akhir Oktober 2020 sebanyak 71 buku terbitan LIPI Press melalui OMP telah terindeks di Google Scholar. Sebanyak 18 buku di antaranya telah disitasi dalam Google Scholar. Selain itu, terdapat 11 buku LIPI Press yang telah memiliki DOI aktif juga telah terindeks Dimensions. Data tersebut menjadikan buku-buku LIPI Press semakin mudah diakses secara global, khususnya bagi akademisi internasional yang mencari referensi melalui situs-situs pengindeks global seperti Google Scholar dan Dimensions. Hal ini juga memberikan alternatif bagi akademisi untuk mempublikasikan hasil penelitiannya dalam bentuk buku melalui OMP, karena selain dapat otomatis terindeks layaknya jurnal, juga memiliki target audiens yang lebih luas.

Pencapaian tersebut membuktikan inovasi LIPI Press dalam mengimplementasikan sistem penerbitan ilmiah daring OMP telah dapat menunjang kebutuhan sitasi dan indeks dari penulis (akademisi) dan instansi. Hal ini menjadi strategis, mengingat indeks dan sitasi, dewasa ini menjadi salah satu tolok ukur produktivitas dan kualitas kegiatan ilmiah. Melalui inovasi ini diharapkan LIPI Press mampu berperan aktif dalam mendorong meningkatnya daya saing ilmiah nasional. 


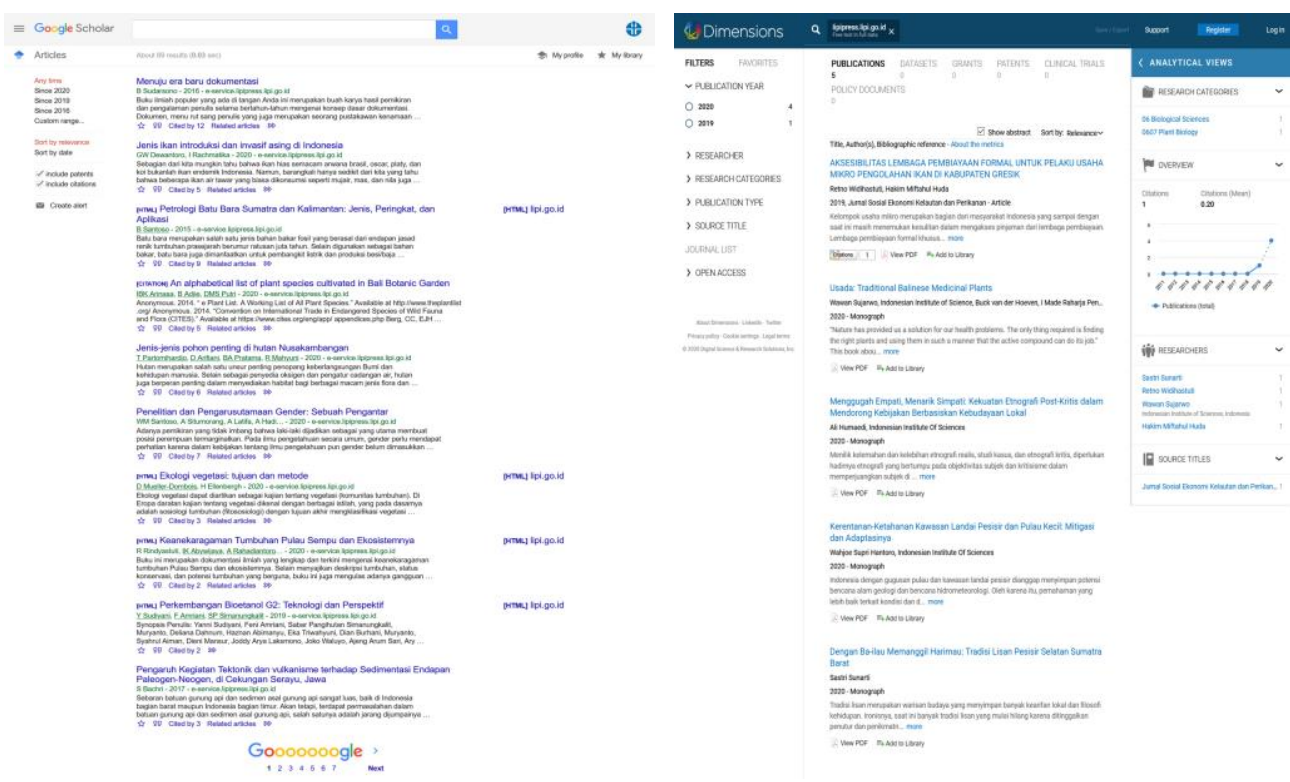

Gambar 3. Terbitan LIPI Press Terindeks Google Scholar dan Dimensions

\section{Kanal Youtube LIPI}

Tahun 2020 LIPI Press meningkat kapasitasnya dengan turut mengakomodasi kebutuhan pengemasan dan diseminasi konten multimedia LIPI. Salah satu fungsi yang diemban atas meningkatnya kapasitas tersebut adalah dalam pengelolaan kanal Youtube LIPI (https://www.youtube.com/channel/UCr1ihEI566IJib9P-JjENSA) sebagai kanal domain publik untuk mendiseminasikan konten-konten multimedia. Semakin merebaknya video conference turut menjadikan peran multimedia semakin strategis, salah satunya pengelolaan fitur livestreaming berbagai webinar yang diselenggarakan oleh satker di lingkungan LIPI melalui kanal Youtube LIPI. Selain livestream webinar, Youtube LIPI juga menjadi kanal publik untuk mendiseminasikan hasil akuisisi pengetahuan lokal berupa karya audiovisual.

Berbagai konten yang semakin variatif dan masif membuat kanal Youtube LIPI telah menembus angka 100.000 subscribers per September 2020. Pencapaian tersebut semakin mempertegas peran multimedia dalam mengakomodasi kebutuhan masyarakat akan informasi ilmiah yang sesuai dengan gaya hidup dan perkembangan teknologi terkini.

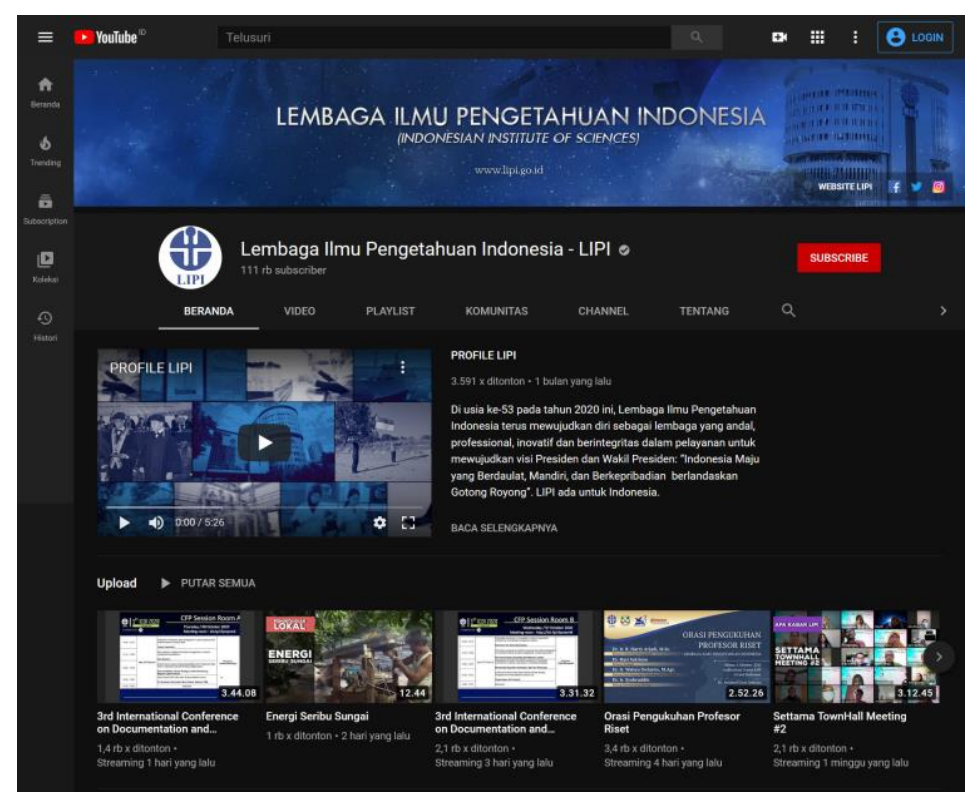

Gambar 4. Kanal Youtube LIPI 


\section{Media Sosial LIPI Press}

Peran media sosial semakin strategis dalam menjaring keterikatan publik yang lebih luas terhadap LIPI Press. Fungsi promosi dan diseminasi yang diemban menjadikan LIPI Press membangun secara serius aspek media sosial, yakni @lipi.press (Instagram), @lipi_press (Twitter), dan Fans Page LIPI Press (Facebook). Media sosial LIPI Press memberikan informasi seluruh layanan publik LIPI Press dan hal lain yang berkaitan, antara lain sebagai berikut.

1) Prosedur penerbitan dan pengajuan permohonan informasi.

2) Program-program yang tengah berlangsung, seperti program akuisisi atau pemagangan.

3) Hasil-hasil pengemasan ilmu pengetahuan, baik berupa buku elektronik maupun multimedia/audiovisual.

4) Kegiatan diseminasi ilmu pengetahuan LIPI Press, seperti knowledge sharing, bedah buku, bimbingan teknis, dan webinar.

5) Berbagi pengetahuan praktis tentang dunia penerbitan, editorial, dan audiovisual yang menjadi core LIPI Press, seperti penggunaan kata baku dan serapan kata.

6) Prestasi dan apresiasi yang diterima oleh LIPI Press.

7) Ucapan hari besar dan informasi lain yang relevan.

Semua informasi melalui media sosial disampaikan secara menarik menyesuaikan dengan kebutuhan dan gaya hidup warganet Indonesia. Diharapkan informasi tentang pelayanan mudah diakses melalui berbagai media sosial LIPI Press.

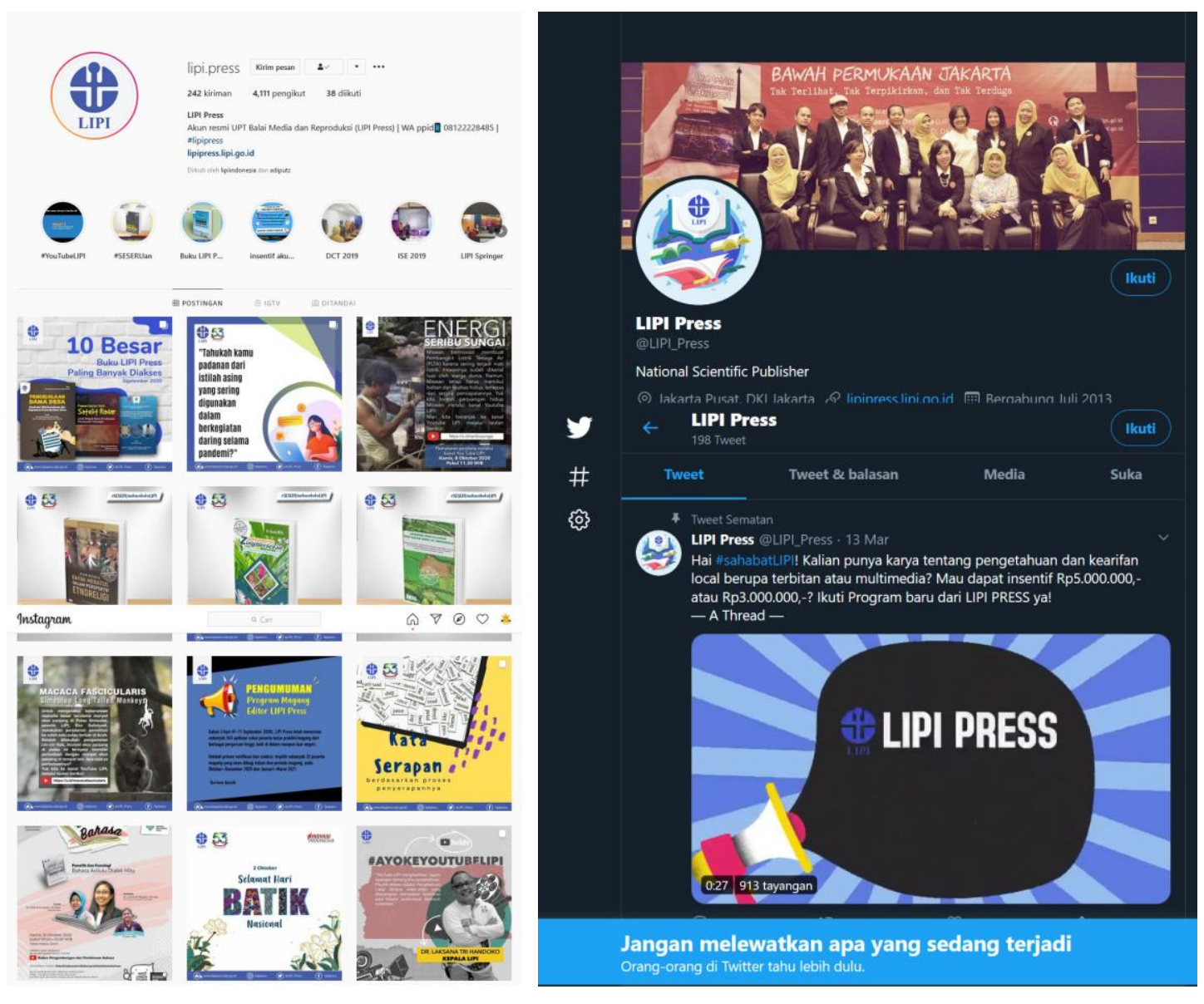

Gambar 5. Media Sosial LIPI Press 


\section{Program Akuisisi Pengetahuan Lokal}

Program akuisisi pengetahuan lokal merupakan salah satu terobosan LIPI Press yang digagas pada awal 2020. Melalui program ini, kapasitas LIPI Press meluas tidak hanya memberikan layanan kepada instansi baik kementerian maupun lembaga tetapi juga masyarakat umum yang memiliki pengetahuan lokal. Prosedur kerja juga mengalami perubahan di mana LIPI Press tidak menarik biaya jasa layanan melainkan mampu memberikan insentif kepada peserta akuisisi. Hal ini berdampak besar pada bergaining power LIPI Press dalam menetapkan standar terbitan ke tingkat yang lebih tinggi.

Program akuisisi LIPI Press sendiri pada prinsipnya bertujuan untuk mengakuisisi pengetahuan lokal dari publik dengan skala nasional, baik dalam bentuk tulisan maupun audiovisual untuk kemudian didiseminasikan secara bebas dalam kanal publik agar bisa menjangkau dan dimanfaatkan oleh lebih banyak orang. Program akuisisi memiliki dimensi kekinian yang sangat strategis karena membangkitkan kembali literasi dalam format multimedia, baik terbitan elektronik maupun audiovisual, dan mengedukasi para kreator konten ilmu pengetahuan, dengan memanfaatkan kanal publik di luar kanal konvensional dalam bentuk buku terbitan. (Suhendra, 2020b)

Diharapkan melalui program akuisisi ini tidak hanya produktif dalam kuantitas jumlah konten pengetahuan melainkan dapat berperan aktif membentuk ekosistem baru kreator konten ilmu pengetahuan

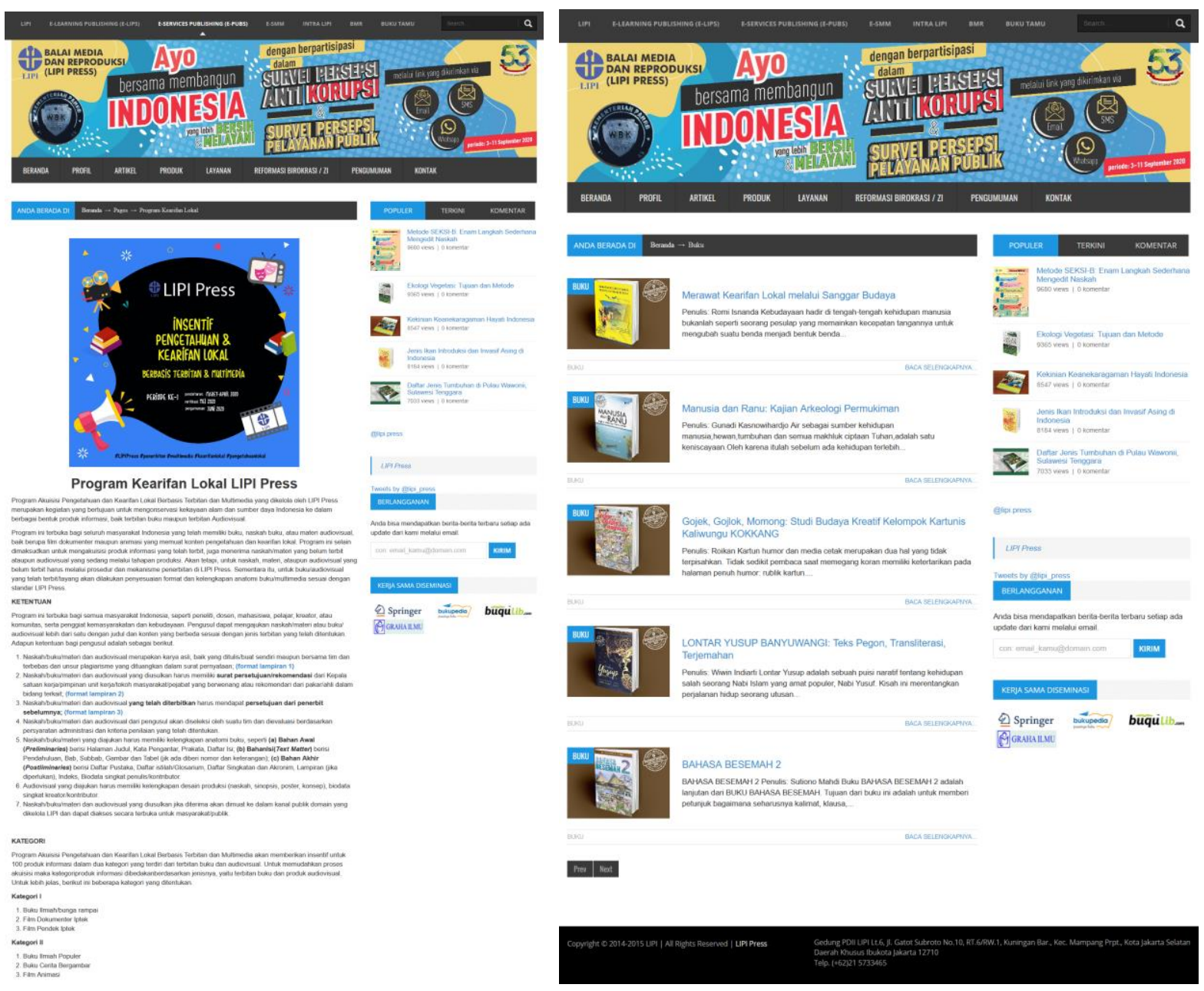

Gambar 6. Program Akuisisi Pengetahuan Lokal dan Hasil Akuisisi (Suhendra, 2020b) 


\section{Layanan Magang bagi Mahasiswa sebagai Bagian Program Kampus Merdeka}

Sejalan dengan kebutuhan sumber daya LIPI Press dan turut menumbuhkembangkan semangat kaderisasi dan knowledge sharing bidang penerbitan ilmiah, LIPI Press pada semester 22020 menyelenggarakan program magang LIPI Press yang diperuntukkan bagi mahasiswa semester 5 ke atas. Selain untuk menjawab minat banyaknya mahasiswa yang ingin menimba pengalaman dan mengaplikasikan ilmunya di LIPI Press, program ini sekaligus menjadi kontribusi LIPI Press untuk turut andil dalam implementasi konsep Merdeka Belajar dengan menyediakan fasilitas magang bagi para mahasiswa yang membutuhkan.

Melalui konsep Merdeka Belajar, LIPI Press memberikan akses dan dukungan bagi mahasiswa untuk menggali pengalaman mereka dalam bidang penerbitan buku dan multimedia ilmiah. Mahasiswa yang mengikuti program magang, diberi kesempatan terjun langsung dalam proses kerja LIPI Press, guna mendapat pengetahuan dan keterampilan baru yang relevan serta dibutuhkan oleh masyarakat dan industri terkait.

Program magang ini mendapat respons yang luar biasa dari mahasiswa terutama karena format Work from Home (WFH) memungkinkan mahasiswa dari luar daerah dapat berpartisipasi tanpa terkendala jarak. Program magang sudah berlangsung dua kali, dengan tahap pertama adalah program magang multimedia yang berhasil menyaring 10 peserta dari 146 proposal yang masuk dengan periode magang Juli-Oktober dan Oktober-Desember 2020. Tahap kedua program magang editor berhasil menyaring 27 peserta dari 543 proposal yang masuk dengan periode mangang Oktober-Desember dan Januari-Maret 2020. (S. P. Dewi, 2020a)
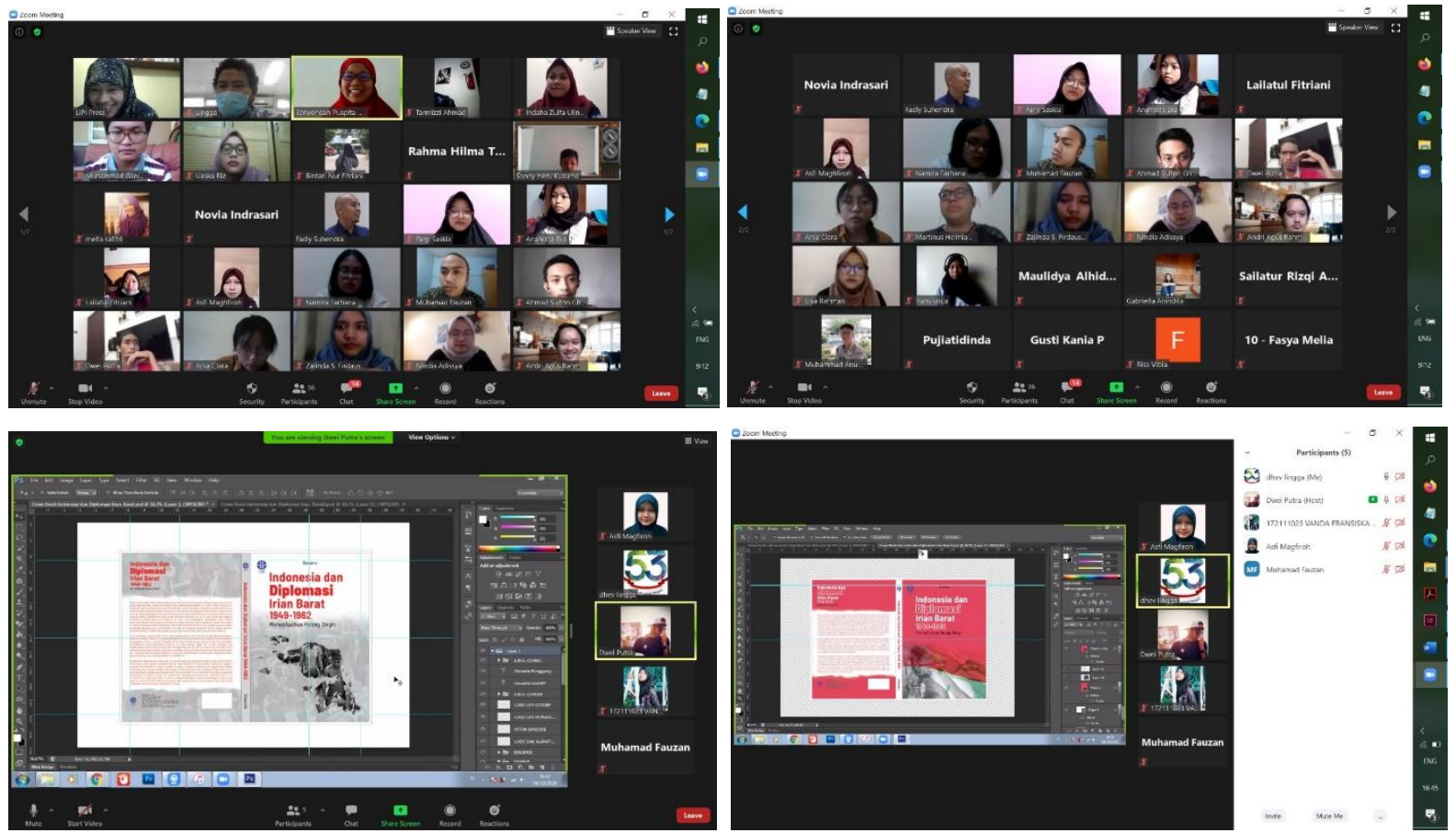

Gambar 7. Seluruh Peserta Program Magang Mengikuti Pembekalan Magang LIPI Press dan Project Progress Meeting Magang Editor Visual via Zoom (S. P. Dewi, 2020a)

\section{Uji Kompetensi Sertifikasi Profesi bagi Editor LIPI Press}

Setiap tahunnya LIPI Press senantiasa mengadakan peningkatan kompetensi bagi civitas dengan materi-materi yang menunjang penerapan budaya layanan prima di LIPI Press. Pada 2020 LIPI Press fokus dalam peningkatan kompetensi staf editor untuk menunjang layanan editorial yang lebih terstandar dan profesional. Untuk itulah pada Rabu, 12 Agustus 2020, LIPI Press menyelenggarakan Uji Sertifikasi Penulis Buku Nonfiksi dan Editor. Kegiatan tersebut terselenggara atas kerja sama dengan Badan Nasional Sertifikasi Profesi (BNSP) melalui Lembaga Sertifikasi Profesi Penulis dan 
Editor Profesional (LSP-PEP). Kegiatan sertifikasi dilaksanakan di Ruang Seminar Lt.2, Gedung PDDI-LIPI dengan peserta 18 staf Editor LIPI Press. (Suhendra, 2020a)

Sertifikasi yang dilaksanakan dengan protokol kesehatan ini sangat penting bagi LIPI Press sebagai satuan kerja di lingkungan LIPI yang memiliki tugas dan fungsi menyelenggarakan kegiatan penerbitan ilmiah. Bagaimanapun penerbitan tidak lepas dari peran editor agar dapat menghasilkan terbitan ilmiah yang terstandar dan berkualitas. Oleh sebab itu sertifikasi kompetensi menjadi salah satu bentuk pengakuan pada profesi editor yang selama ini dijalani. Dengan adanya sertifikasi diharapkan dapat menjadi pemicu agar kinerja layanan editorial menjadi lebih terstandar dan profesional melalui staf editor yang layak dan kompeten.
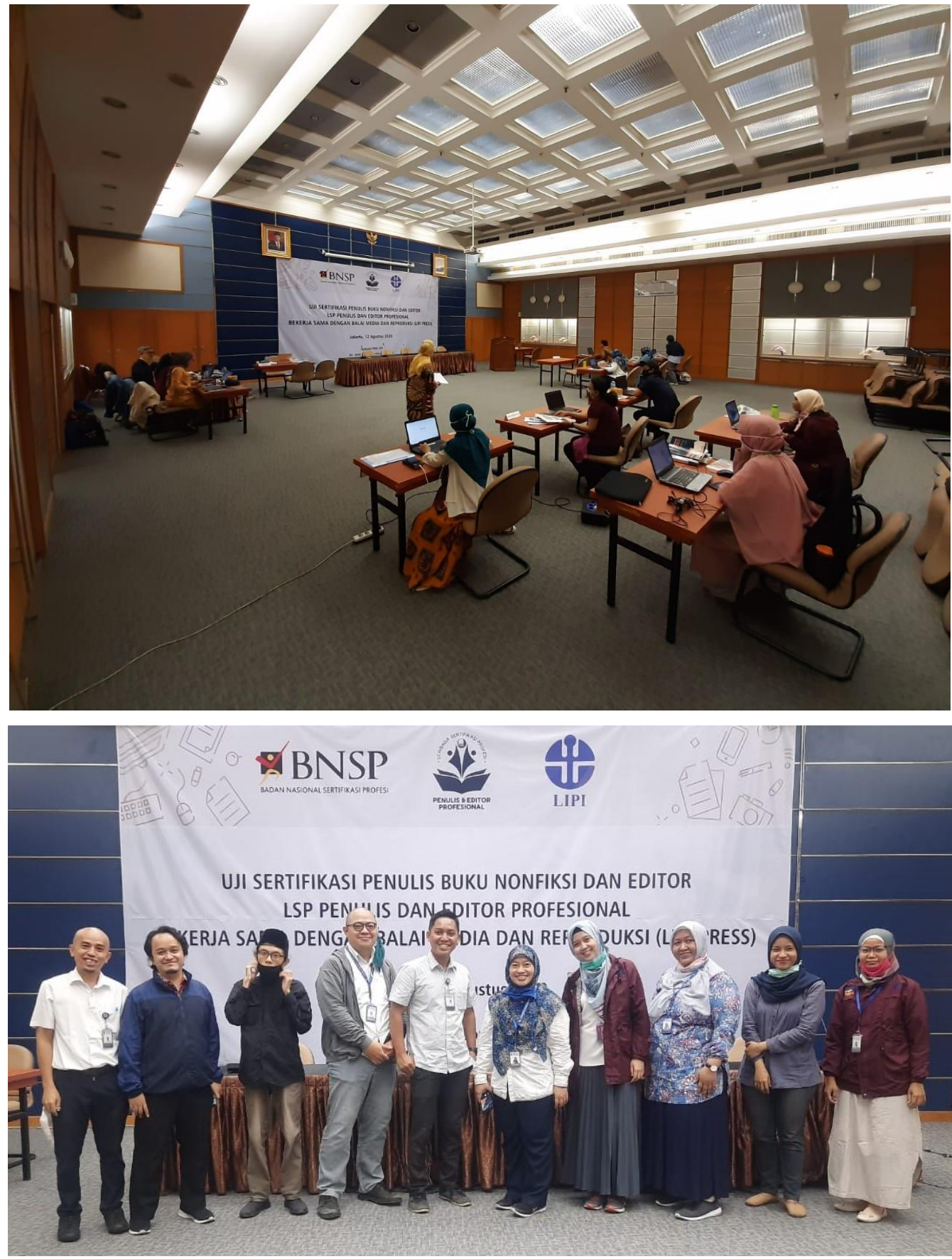

Gambar 8. Uji Sertifikasi Staf Editor LIPI Press (Suhendra, 2020a) 


\section{Bedah Buku melalui Webinar}

Kegiatan bedah buku LIPI Press adalah salah satu satuan bentuk layanan pendukung penerbitan hasil-hasil penelitian LIPI yang layak diketahui oleh publik. (Press, 2014) Bedah buku menjadi ajang berbagi pengetahuan hasil-hasil riset penelitian yang dikemas dalam bentuk buku ilmiah. Diharapkan masyarakat dapat merasakan dan mengetahui kontribusi LIPI bagi kemajuan negeri.

Berbeda dengan tahun-tahun sebelumnya, bedah buku yang diselenggarakan LIPI Press selama 2020 berkonsep webinar. Webinar sendiri merupakan presentasi akademis daring secara langsung, di mana pemirsa yang berpartisipasi dapat mengirimkan pertanyaan dan komentar. (Merriam-Webster, 2020) Webinar LIPI Press menggunakan media video konferensi Zoom yang merupakan layanan konferensi video kolaboratif berbasis cloud yang menawarkan fitur termasuk rapat daring, layanan perpesanan grup, dan perekaman sesi konferensi untuk di simpan pada sistem cloud maupun komputer lokal. Seperti platform serupa yakni Skype, Zoom menawarkan kemampuan untuk berkomunikasi secara real time dengan individu yang tersebar secara geografis melalui komputer, tablet, atau perangkat seluler. (Archibald et al., 2019; Mahelingga, 2020d; Zoom Video Communications Inc., 2016) Beberapa bedah buku LIPI Press selama 2020 adalah sebagai berikut.

\section{a. Bedah Buku Termometer Inframerah: Teori dan Kalibrasi}

Bedah Buku Termometer Inframerah: Teori dan Kalibrasi diselenggarakan via Zoom pada Senin, 24 Agustus 2020. Buku tentang termometer sengaja diangkat di tengah meningkatnya penggunaan termometer inframerah atau thermo gun di masa pandemi Covid-19. Terlebih beberapa waktu belakangan, sempat muncul isu yang menimbulkan keresahan di sebagian masyarakat, seperti beredarnya thermo gun palsu atau isu bahaya thermo gun bagi otak.

Bedah buku ini membahas fakta ilmiah terkait fungsi dan cara kerja penggunaan thermo gun, hal-hal terkait radiasi termometer dan peran penting kalibrasi bagi termometer inframerah. (Wiriadinata, 2015)

\section{b. Bedah Buku Perempuan Kepala Daerah, Oligarki, dan Penanggulangan Kemiskinan Berperspektif Gender}

Webinar bedah buku bertajuk "Knowledge Sharing dan Bedah Buku: Perempuan Kepala Daerah, Oligarki, dan Penanggulangan Kemiskinan Berperspektif Gender" dilaksanakan pada Senin, 14 September 2020. Acara tersebut dihadiri oleh 89 peserta yang berasal dari berbagai kalangan, seperti dosen, mahasiswa, dan masyarakat pemerhati gender serta pemilihan kepala daerah.

Kegiatan webinar ini bertujuan untuk melihat sisi lain perempuan, khususnya sebagai kepala pemerintahan di tingkat lokal, termasuk peran dan kinerja perempuan dalam merencanakan, menyusun, dan melaksanakan program kerja selama masa jabatan. Selain itu, acara ini juga dimaksudkan agar publik semakin awas dan waspada terhadap berita-berita yang menyangkut gender, perempuan, dan kepala daerah menjelang ajang pemilihan kepala daerah pada 9 Desember. (K. H. Dewi et al., 2020; S. P. Dewi, 2020b)
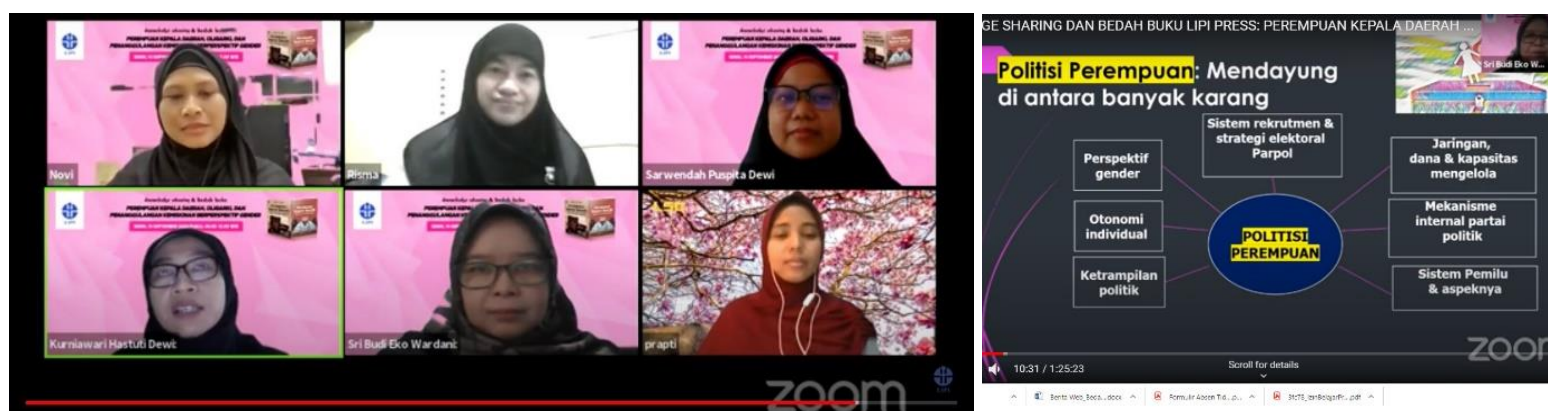

Gambar 9. Bedah Buku Perempuan Kepala Daerah, Oligarki, dan Penanggulangan Kemiskinan Berperspektif Gender (S. P. Dewi, 2020b) 


\section{c. Knowledge Sharing: Dibalik Produksi Borobudur Lalitavistara Flora Fauna Relief}

Knowledge Sharing: Dibalik Produksi Borobudur Lalitavistara Flora Fauna Relief merupakan ajang berbagi ilmu pengetahuan bersama para peneliti dan kreator audiovisual LIPI yang dilaksanakan pada Kamis, 1 Oktober 2020 pukul 10.00-12.00.

Lalitavistara adalah kitab Buddha dalam bahasa Sansekerta. Pada lapisan relief Lalitavistara di candi Borobudur berisi kisah hidup dan ajaran Sang Buddha Gautama. Knowledge sharing menghadirkan Dr. Cahyo Rahmadi, Destario, M.Sc, Gravinda Putra, dan Arief Hermawan yang akan berbagi cerita tentang penelitian dan kolaborasi kreatif sehingga menjadi film dokumenter ilmu pengetahuan.

\section{d. Workshop: Di Balik Produksi Animasi Bertanya Sains LIPI Series}

Workshop: Di Balik Produksi Animasi Bertanya Sains LIPI merupakan ajang berbagi pengalaman proses kreatif di balik produksi "Animasi Bertanya Sains LIPI". Kegiatan ini berlangsung beberapa kali antara lain 30 Juli, 6 Agustus, dan 5 Oktober 2020.

Workshop membahas bagaimana cara sivitas kreatif LIPI mengonversi laporan riset yang dihasilkan oleh para peneliti LIPI ke dalam bentuk visual animasi atau motion graphic sehingga dapat dinikmati oleh publik. Kegiatan menghadirkan Penny Sylvania Putri, Mutia Maritha, dan Laura Citra selaku pembicara yang merupakan sivitas LIPI Press yang selama ini berada di balik produksi video "Animasi Bertanya Sains LIPI". Selain mendapatkan materi, peserta sekaligus belajar membuat karya animasi sederhana.

\section{Knowledge Sharing Teknis Kinerja melalui Zoom}

Sebagai bentuk percepatan penerapan budaya layanan prima, LIPI Press menyelenggarakan forum berbagi pengalaman dan pengetahuan teknis penerbitan. Beberapa di antaranya adalah dalam bidang penyuntingan dan pemanfaatan teknologi informasi untuk mendukung layanan penerbitan. Forum tersebut adalah sebagai berikut.

\section{a. Bimbingan Teknis Penyuntingan Naskah}

LIPI Press menyelenggarakan Bimbingan Teknis Penyuntingan Naskah via Zoom dengan narasumber Muhammad Fadly Suhendra, S.Ikom. dan moderator Meita Safitri, S.Sn. Kelas daring ini dilaksanakan pada Kamis, 18 Juni 2020 pukul 09.30-12.00 WIB dan membahas pengetahuan seputar penyuntingan naskah, pengalaman penyuntingan, dan kiat-kiat menulis ilmiah.

\section{b. Bimbingan Teknis Pembuatan dan Pengiriman Sertifikat Elektronik secara Otomatis}

Bimtek yang dilaksanakan pada 30 September 2020 ini dipandu oleh Dhevi EIR Mahelingga. Bimtek merupakan salah satu ajang berbagi pengalaman dalam memaksimalkan potensi aplikasi daring untuk menunjang penerapan budaya layanan prima di LIPI Press. Belakangan ini webinar semakin ramai dan menuntut perubahan budaya kinerja dari yang sebelumnya manual menjadi by system atau otomatis. Salah satunya dalam mekanisme pembuatan formulir daftar hadir dan pembuatan sertifikat elektronik yang semakin jamak digunakan.

Melalui bimtek ini diharapkan peserta khususnya staf LIPI Press memiliki keterampilan dalam menggunakan aplikasi daring dari Google, seperti Google Drive, Google Form, Google Spreadsheet, dan Google Slide untuk menunjang kinerja layanan. Hal ini selain aplikasi tersebut gratis, juga mudah digunakan karena sudah familiar dalam kehidupan sehari-hari. Di sisi lain aplikasi tersebut memiliki fungsi yang mempermudah kinerja, salah satunya dalam memproduksi sertifikat elektronik ratusan lembar dan mengirimkannya pada masing-masing email peserta. Perubahan kinerja yang lebih efektif dan efisien berbasis teknologi informasi ini merupakan bagian dari semangat aksi agen perubahan LIPI Press. 


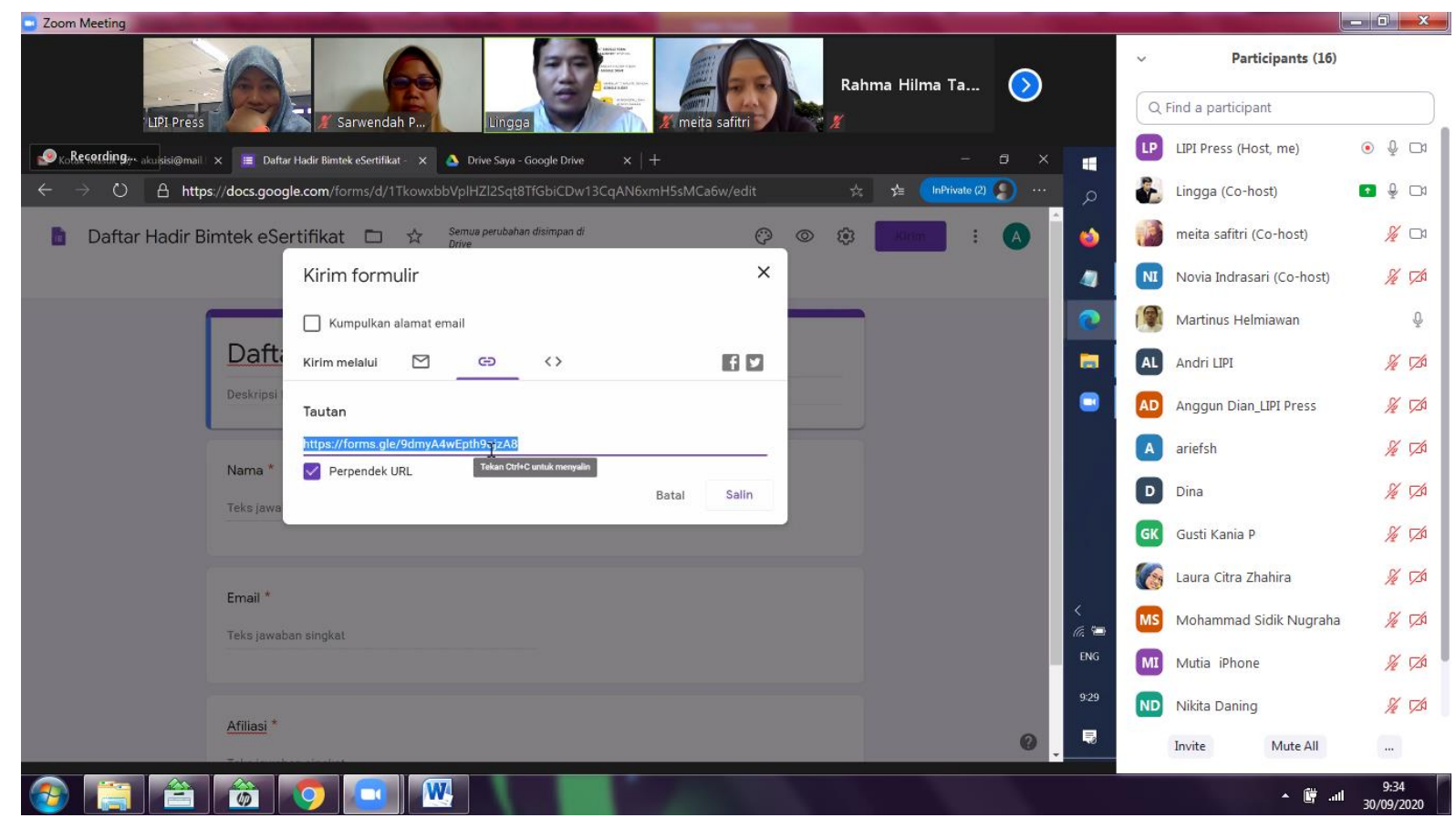

Gambar 10. Bimbingan Teknis Pembuatan dan Pengiriman Sertifikat Elektronik secara Otomatis

\section{c. Knowledge Sharing Penggunaan Mendeley}

Knowledge sharing internal lainnya adalah Knowledge Sharing Penyusunan Kutipan dan Daftar Pustaka serta Penggunaan Mendeley. Kegiatan dipandu oleh Martinus Helmiawan berlangsung pada 16 Oktober 2020 dengan peserta kegiatan adalah editor internal, mitra editor, dan peserta magang LIPI Press 2020.

Secara umum, Mendeley memudahkan dalam fungsi manajerial, akses PDF, penulisan kutipan, dan bibliografi/daftar pustaka. Segala perubahan yang dibuat dalam aplikasi Mendeley akan berdampak pada kutipan dan bibliografi di program pengolah kata seperti Ms Word. (Mahelingga, 2020c)

\section{Kuis Interaktif sebagai Alternatif Knowledge Sharing Editorial}

Sebagai alternatif sarana berbagi pengetahuan dengan cara yang mengasyikan, LIPI Press menyusun kuis interaktif "Tebak Kata LIPI Press" berbasis platform Kahoot untuk para staf editor. Kegiatan yang dibalut dengan semangat santai penuh canda namun tetap berbobot karena materi-materi yang disampaikan berasal dari Kamus Besar Bahasa Indonesia (KBBI) V dan Pedoman Umum Ejaan Bahasa Indonesia (PUEBI).

Kegiatan ini diadakan di sela-sela kegiatan yang sifatnya resmi seperti rapat atau monev. Selain mampu menjadi ice breaking, diharapkan mendatangkan manfaat dan pengetahuan bagi para peserta kuis. Kegiatan serius tapi santai dalam berbagi pengetahuan ini menjadi salah satu kegiatan aksi agen perubahan LIPI Press. 

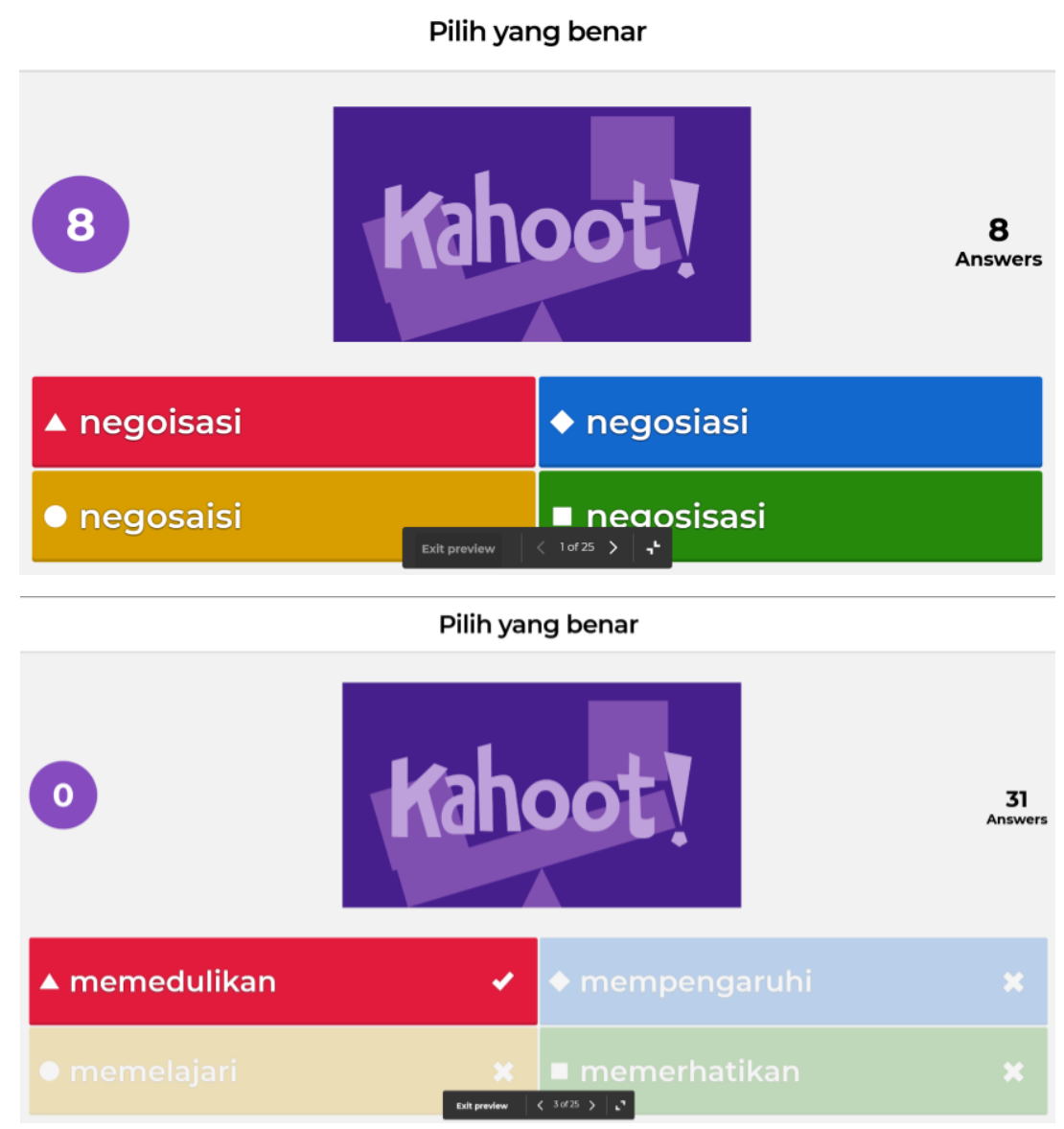

Gambar 11. Kuis Interaktif sebagai Alternatif Knowledge Sharing Editorial

\section{Indeks Kepuasan Masyarakat LIPI Press}

Setiap tahun LIPI Press melakukan survey indeks kepuasan masyarakat (IKM) terhadap layanan LIPI Press secara daring menggunakan Google Form. Hasil survei dan analisis IKM sesuai Permenpan No.25/M.PAN/2/2004 dapat diakses melalui tautan https://lipipress.lipi.go.id/pages/indekskepuasan-masyarakat

Hasil survei kepuasan masyarakat terkait layanan penerbitan tahun 2019 berhasil menjaring 48 responden dan mendapatkan hasil indeks 3,53 atau nilai konversi 88,36 dengan kategori 'sangat baik'. Meski demikian, perbaikan berkelanjutan perlu dilakukan LIPI Press untuk meningkatkan kinerja waktu proses review substansi dan penyuntingan teknis yang menjadi perhatian dari hasil responden. Penyamaan persepsi terkait kaidah, format, dan ketentuan yang baku sebuah buku (ilmiah) perlu dilakukan dengan para pemangku kepentingan.

LIPI Press terus menyosialisasikan proses penerbitan buku (ilmiah) kepada para pemangku kepentingan, baik melalui tatap muka langsung, konsultasi melalui media sosial, maupun sistem yang terintegrasi dalam lipipress.lipi.go.id. Hal tersebut untuk memupus stigma 'proses penerbitan yang lama' yang menjadi keluhan terbesar dari responden pengguna layanan. Sebagai perbandingan durasi penerbitan, LIPI Press semestinya dibandingkan dengan penerbit sejenis (penerbit ilmiah), misalnya Springer dan Elsivier yang memiliki reputasi internasional.

Hasil masukan responden yang disampaikan pada survei IKM ditindaklanjuti dalam rapat monitoring dan evaluasi serta didokumentasikan dalam perbaikan prosedur layanan penerbitan. 


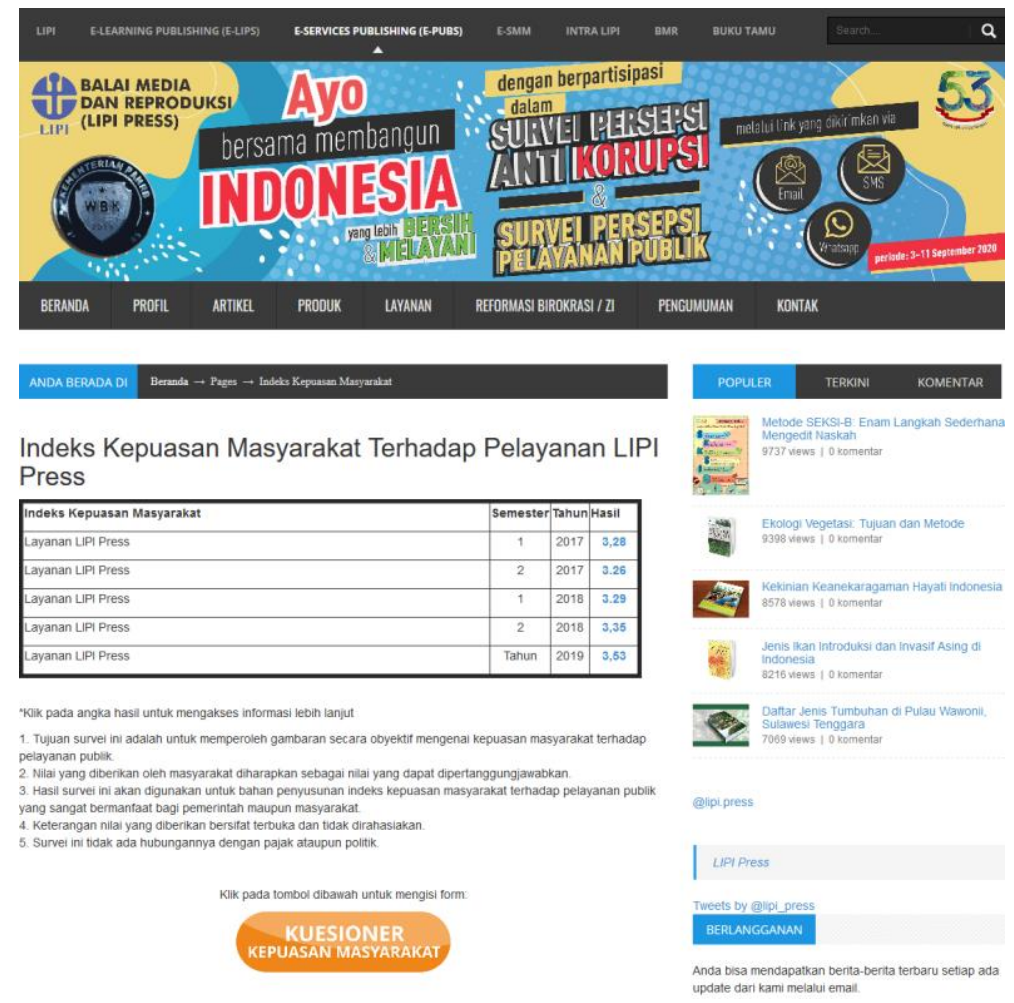

Gambar 12. Indeks Kepuasan Masyarakat LIPI Press di Website

\section{PENUTUP}

Beberapa inovasi telah dilakukan oleh LIPI Press, di antaranya dalam sistem penerbitan ilmiah daring (e-service) berbasis Open Monograph Press (OMP) yang mendukung kebutuhan layanan terintegrasi, baik dari sisi penerbit maupun pengguna layanan. Dari sisi konten, layanan LIPI Press mengalami perubahan signifikan, dari sebelumnya hanya naskah terbitan buku menjadi berkembang dengan turut berperan dalam pengelolaan Open Journal System (OJS) seluruh LIPI dan mengakomodasi pengemasan serta diseminasi konten-konten multimedia.

Segala perubahan kebijakan dan langkah inovasi yang diambil terntunya berangkat dari pertimbangan strategi berbasis kemajuan teknologi informasi. Terlebih dengan adanya pandemi Covid19 memacu LIPI Press untuk lebih dinamis karena kendala ini justru dapat menjadi momentum untuk internalisasi segala perubahan ke arah interaksi digital, e-office, pemanfaatan media sosial, dan konferensi video, dengan luaran terbitan elektronik dan audiovisual.

Kuantitas layanan LIPI Press yang semakin beragam tentunya harus diiringi dengan peningkatan kualitas. Peningkatan kualitas pelayanan publik bertujuan untuk meningkatkan kinerja pelayanan publik LIPI Press melalui serangkaian inovasi dan kegiatan yang sesuai dengan kebutuhan dan umpan balik dari publik atau pengguna layanan. Tolok ukur keberhasilan layanan publik LIPI Press diharapkan bermuara pada peningkatan kepuasan publik dan pengguna layanan terhadap layanan LIPI Press.

\section{DAFTAR PUSTAKA}

Archibald, M. M., Ambagtsheer, R. C., Casey, M. G., \& Lawless, M. (2019). Using Zoom Videoconferencing for Qualitative Data Collection: Perceptions and Experiences of Researchers and Participants. International Journal of Qualitative Methods, 18, 1-8. https://doi.org/10.1177/1609406919874596

Dewi, K. H., Aziz, N. L. L., \& Raharjo, S. N. I. (2020). Perempuan Kepala Daerah dan Penanggulangan Kemiskinan Berperspektif Gender di Indonesia. LIPI Press. 
Dewi, S. P. (2020a). Hanya Tiga Hari, Program Magang LIPI Press 'Diserbu' 543 Pelamar. LIPI Press. https://lipipress.lipi.go.id/detailpost/hanya-tiga-hari-program-magang-lipi-press-'diserbu'543-pelamar

Dewi, S. P. (2020b). Knowledge Sharing dan Bedah Buku: Perempuan Kepala Daerah. LIPI Press. https://lipipress.lipi.go.id/detailpost/knowledge-sharing-dan-bedah-buku-perempuan-kepaladaerah

Perka LIPI No. 6 Tahun 2020 tentang Organisasi dan Tata Kerja Balai Media dan Reproduksi, 1 (2020). https://jdih.lipi.go.id/peraturan/2020_Peraturan LIPI_6.pdf

Mahelingga, D. E. I. R. (2020a). Panduan Praktis Mengirim Naskah via Open Monograph Press 3.2 LIPI Press. https://doi.org/10.31219/osf.io/x4npd

Mahelingga, D. E. I. R. (2020b). Penerbitan buku ilmiah daring berbasis open monograph press (OMP). Berkala Ilmu Perpustakaan, 16(2), 155-169. https://doi.org/10.22146/bip.v16i1.265

Mahelingga, D. E. I. R. (2020c). Pengenalan Manajemen Referensi Mendeley. https://doi.org/10.31219/osf.io/g2yrj

Mahelingga, D. E. I. R. (2020d). Webinar dan akses ebook di masa pandemi Covid-19. https://doi.org/10.31219/osf.io/vcgxa

Merriam-Webster. (2020). Definition of Webinar by Merriam-Webster. https://www.merriamwebster.com/dictionary/webinar

Press, L. (2014). Pedoman Penerbitan Buku LIPI Press. Jakarta.

Schwarz, M., Scherrer, A., Hohmann, C., Heiberg, J., Brugger, A., \& Nuñez-Jimenez, A. (2020). COVID-19 and the academy: It is time for going digital. Energy Research and Social Science, 68(June), 0-2. https://doi.org/10.1016/j.erss.2020.101684

Suhendra, M. F. (2020a). Editor LIPI Press Jalani Uji Kompetensi Sertifikasi Profesi. LIPI Press. https://lipipress.lipi.go.id/detailpost/editor-lipi-press-jalani-uji-kompetensi-sertifikasi-profesi-

Suhendra, M. F. (2020b). Program Insentif Pengetahuan \& Kearifan Lokal. LIPI Press. https://lipipress.lipi.go.id/detailpost/program-insentif-pengetahuan-amp-kearifan-lokal

Wiriadinata, H. (2015). Termometer Inframerah: Teori dan Kalibrasi. LIPI Press.

Zoom Video Communications Inc. (2016). Zoom Security Guide. Zoom Video Communications Inc. 